\title{
Reflection on the Developing of the Network Courseware of Specialized Course for Engineering College Students
}

\author{
Biqiong Li \\ College of Automobile and Machinery \\ Changsha University of Science and Technology, CSUST \\ Changsha, China \\ libiqiong02@126.com
}

\author{
Qing $\mathrm{Hu}$ \\ College of Automobile and Machinery \\ Changsha University of Science and Technology CSUST \\ Changsha, China \\ 178310005@qq.com
}

\author{
Qilong Wang \\ College of Automobile and Machinery \\ Changsha University of Science and Technology CSUST \\ Changsha, China \\ 410824856@qq.com
}

\begin{abstract}
This paper discusses existing problems about how to study specialized course for engineering college students, how to develop the network courseware and to rich teaching resources, and to make up a deficiency of practical links with the points of view of teachers in colleges and Universities teaching by using the Multi-media network course. And existing problems between design teaching model are analysed according to characteristic of learning object. Take technology of mechanical manufacture for example, this paper explains how to design and develop a software of specialized course, which can do exercise classify, and teach through lively activities, in order to improve students' interest in specialty learning. This is a useful experiment to auxiliary teaching of the network courseware.
\end{abstract}

Keywords-network course; specialized course; instructional software

\section{INTRODUCTION}

Network education develop earlier in foreign countries, people research more teaching and study based on network, there are more practice experience and theoretical exploration about network learning theory and learning model and learning environment as well as construction and administration of resources. In network learning monitoring, remote teaching for western students not to rely on face to face teaching, while learning content and method are choiced by themselves instead of controlled by teacher[1].

From the perspectives of , the network education in china still be in the primary stage of development, accumulation of theory and practice still to deepen. Through searching it is not difficult to find that on the whole informatization and network of education resources still insufficient for colleges and universities in china although there is website in each universities, and there are electronic public class and excellent course in many universities to be browsed, while network education are vigorously developed in the word's top universities such as Harvard and Yale, so not only show yourself fully but also cultivating more reserve source[2]. But in recent years, the problem on quality monitoring system is concerned by our network education field, frame of learning control and evaluation are constructed from a theoretical points of view and a set evaluation of technical scheme of network learning which process oriented is put forward by Mei Cao in Nanjing Normal University which take students evaluation as a means of network learning monitor.

Network teaching platform of Vclass which developed by Bejing Normal University realized functions as targeted counselling to learner and taking notes in stidies lay a foundation for a follow-up study and to provide a train of thought and to be helpful to individualized teaching[3], but there is very seldom literature about network learning method and teaching strategy of a course.

Accompanied by rapid development of science and technology and teaching content change rapidly and increasing and teaching hours relative tension and paper teaching resources unable to keep up with knowledge to bring forth the new through the old speed, so it is difficult to adapt to this new situation for traditional teaching model and unable to meet the requirement of course teaching quality in the limited teaching time. With the emergence and development of computer and network technology and which application in the field of teaching, they have the advantages such as across time and space and easy to get rich teaching resources and can increase the teaching quantity, so it can solve the above contradiction.

\section{LEARNING OBJECT ANALYSIS}

Because of special education system and the pressure of the college entrance examination in our country, students in our country are in the habit of text reciting and theoretical 
derivation from primary school and middle school to University, stress in social needs and practice and practical ability is not mech. After entering the university, the school curriculum for the first grade of university and the second grade university engineering students are still basic theory course. Students in the western countries such Europe and the United States are required pay attention to book knowledge, at the same time to participate in social practice activities from a child to grow up, school and enterprise close contact, their college students have more oppprtunities to practice in enterprises and their practice ability are exercised fully. But in our country, it can not copy the mode of training students of developed coutry such as Europe and the United States because of characteristic of enterprise management system and there are many university so as to the number of college students. In front of us an important issue is that how the existing conditions improving the students' practical ability and study the specialized courses and to learn in order to practice, quickly adapt to the business needs of the production.

You can say that students' learning characteristic in our country is used to study theory, but social practice and ability remains to be improved. When engineering students enter the university the third grade and access to professional class, they often be nonplussed over something because of they have no engineering background and one the production site lack perceptual knowledge and be not well understood textbook content, this is a professional course teaching and learning to bring no small pressure.

Students which enter the university the third grade are in upward knowledge age, when they start learning course such as Machinery manufactureing technology and fixture design, their theoretical basis of knowledge is full and wish to have achieved. Although students are aware of the importance of the curriculum, but learning enthusiasm still not tall, one of the questions most frequently is : 'what is the use which we learn in this course, teacher?' after several communication the main reason of the existence of these problems are the concept of enterprise very strange to them and only in the minds of the imagination, they fell that many of these terms, the theory is very empty, so they are incapable of action because of fear of this course.

The author thinks that first should let the students from psychological to overcome the fear of this course, to make them aware of being able to learn specialized course in spite of difficult if they try hard.

The core of teaching design is change from 'how to teach' to 'how to learn' with the exploitation of network courseware; secondly in the teaching process teachers should play a guiding role, 'stimulate students interest in learning, to help the students to form a learning motivation; help students to construst the current knowledge meaning by creating consistent with teaching content requirements of the situation and tips for new, old knowledge links between cues.

\section{Design OF TEACHING MOdeL}

Design of teaching model should meet learners in the learning process to need as far as possible firstly, second help learners master the modern education thought reflects the various ability such as self study ability, innovation ability, self evaluation, cooperation ability, scientific research ability ect. The model reflects the idea that as far as possible to meet the learners to master the knowledge and skills required for learner to prepare, to cultivate the moden education thought embodies the ability as the center[4,5].

The cultivation of students' ability in teaching activities is an important target no matter what kind of teaching methods. It is should adopt different teaching organization model, design and use different teaching methods according to the different types of curriculum and different ability training objectives[6].

For example, when talking of get the size precision of method, there are 4 kinds of methods such as trial cutting method, adjustment method, sizing tool method, automatic control method ect. The former student of the 4 methods is not easy to understand. Here, we begin with a brief introduction to the characteristics of various methods and the scope of application, then the animation demo, in the game teaching like this, it is easy for students to understand. When talking of the method of obtaining the position accurary. It is necessary to use animation to illustrate. This animation is in the plane of the borehole, hole center line relative to the plane of verticality depend on drill bit feeding direction and work bench or fixture locating surface verticality, the original error which may occur in the processing show as the the chart format, let students to understand at a glance. When talking of pure angle swing of spindle rotation to influence of processing precision, you can still get a circular workpiece when turning, but the workpiece is a cone, bored holes for oval when in the boring machine boring, this process enable students to remember with the animation demo.

\section{DESIGN AND DEVELOPMENT OF PROFESSIONAL COURSE OF SOFTWARE SYSTEM}

Interactive and timely exercise is very important in network teaching, a set of specialized course learning software system is developed in order to strengthen the knowledge and understand abstract concepts, the system includes a set of grade exercise after class and the auxiliary teaching material content which can expand the focus and difficult. Graded exercise is designed according to the learning content of each unit. Problem in the process of encounter problems, the answer to the question or problem solving method are not provided directly to learners, but a guide, to allow the learner to solve the problem and learning rules, strategies and methods. For example, when talking of the process dimension chain, a five dimensional chain game animation is designed in order to understand the concept of growth ring, reduced ring for students, in the animation, green box which written by growth ring or reduced ring is picked out by students from the original object placed district and placed into the corresponding A1, A2, A3 , A4, if answered correctly, with a short tip; if answered incorrectly, the box go back to the original position, and that answer wrong, again, until all correct, the system will have to encourage language : congratulations on your right. Graded exercise design from easy to difficult, like playing computer games, but in front of the right answer, can enter into the next problems. If no answer, there will be a short notice; 
the answer, there will be encouraging language or electronic gifts. For example, in the dimension chain calculating graded exercise, calculation, incerse calculation and intermediate calculation are included, from simple 3 rings size chain to polycyclic dimension chain, from a purely computational to comprehensive practice. Which that is a machining process of a part of are given, firstly, according to process content analysis and judgment by students who application of dimension chain principle, the dimension chain is drawn and the character of each component link is judged, then the numerical calculation, the final results are obtained, in the mastery of this part of the exercise at the same time cultivation of interest in learning for students through this interactive.

It is necessary to increase the number of auxiliary materials in order to understand deeply the key and difficult content for students and make up for the lack of practical experience, enhance students' perceptual knowledge on production site and expand horizons. There are mainly image data in this part, may some of the topics such as holes' conventional machining methods, typical equipment for hole processing, conventional machining methods for plane, assembly process for product ect.

The system is designed to be very complex in order to purse function and the entire of system in some colleges and universities, the results make teacher and students step back . so when system is designed, never not essential module, strive to make the interface is simple and easy to understand for more complex module, in the design at the same time trial and modify when system is designed.

Refer to the popular network education system and considering the characteristics of Higher Education Aided Teaching, strive to advanced design concept into the system of education and the whole system is simple and practical.

\section{CONCLUSIONS}

Hough many years of professional course teaching, the author deeply recognized that the teachers' teaching methods, techniques plays a very important role to promote students learning the professional course; it is very important while the development of excellent courses learning network courseware, let the students easy access to abundant teaching resources, play advantage of multimedia network in university education and teaching activities.

\section{ACKNOWLEDGEMENTS}

This work was supported by Teaching reform research project of Changsha University of Science and Technology.

\section{REFERENCES}

[1] Xin Xie, Lin Chen, Information systems research in Distance Education Management, Oct. 2008

[2] Jie Lian, Zhiyong Tan, Simple Talking About Network Teaching System Structure, Journal of Chifeng University, Vol.24 No.4, Aug.2008

[3] Wen Tian, Several ponders on network teaching and network courseware for teachers in colleges and Universities, Journal of Guangdong polytechnic, No.5, 2008

[4] Min Li, design concept of multimedia courseware-the integration of technology and art, Fujian computer, No.10,2008
[5] Xuefeng Zhang, College teaching multimedia network system based on two mainpatterns, Journal of Changchun University, August,2008

[6] Aidong $\mathrm{Li}$, the application of modern educational technology in the course teaching design of management information system, Journal of Zhenjiang Polytechnic College, Vol 21, No.3, 2008 